NISTIR 7854

\title{
Guidelines for NIST Staff Participating in Documentary Standards Developing Organizations'Activities
}

http://dx.doi.org/10.6028/NIST.IR.7854

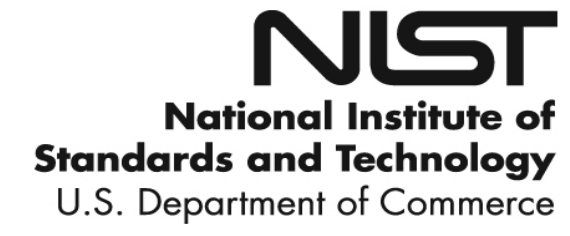


NISTIR 7854

\title{
Guidelines for NIST Staff Participating in Documentary Standards Developing Organizations'Activities
}

\author{
Nathalie Rioux \\ Erik Puskar \\ Mary Jo DiBernardo \\ Standards Coordination Office \\ Standards Services Group
}

http://dx.doi.org/10.6028/NIST.IR.7854

August 2012

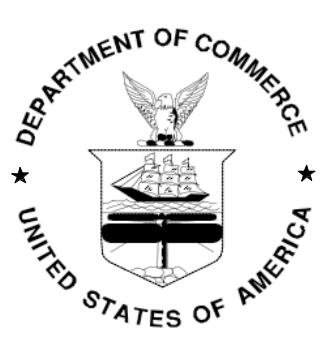

U.S. Department of Commerce

John E. Bryson, Secretary

National Institute of Standards and Technology Patrick D. Gallagher, Under Secretary of Commerce for Standards and Technology and Director 


\section{PREFACE}

These guidelines were prepared by the Standards Coordination Office's (SCO) Standards Services Group (SSG). SCO is responsible for coordinating government-wide standards and conformity assessment activities with those of the private sector. Additionally SCO coordinates NIST participation with voluntary consensus standards organizations. This revision of the November 2005 Guidelines provides background, guidance and resources for NIST staff, and the management that supports these activities, on participating in voluntary standards activities.

Standards Services maintains the Standards Services (http://inet.nist.gov/adlp/services/standards- servicesgroup.cfm) website to provide NIST staff with information on standards-related activities both inside and outside of NIST. Many of the other links and references in this document may be found on www.standards.gov, and on the Global Standards Information site: http://gsi.nist.gov/global/index.cfm.

We welcome your input on this document. Please forward suggestions for improvements, comments or questions to SCO at ext. 4000 or ssg@nist.gov. 


\section{Table of Contents}

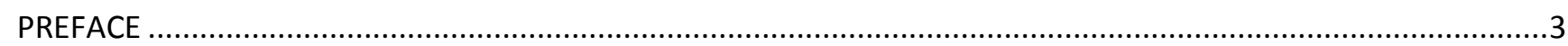

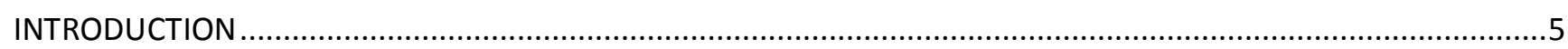

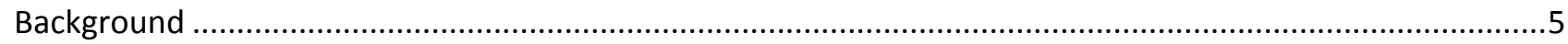

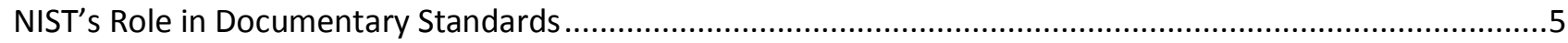

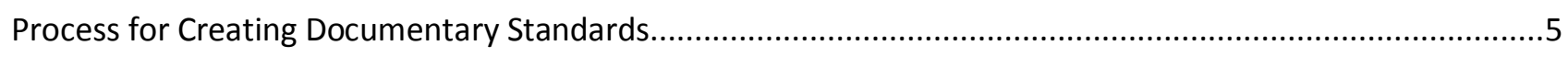

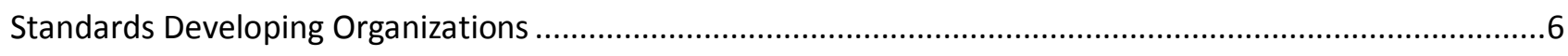

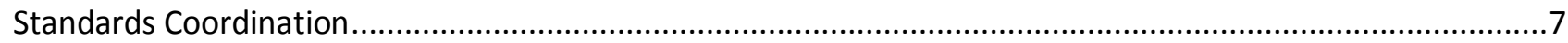

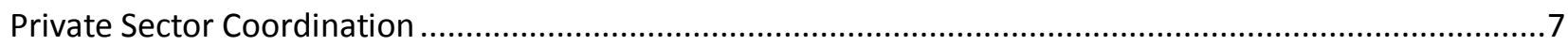

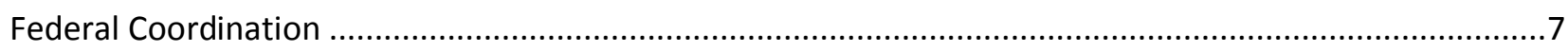

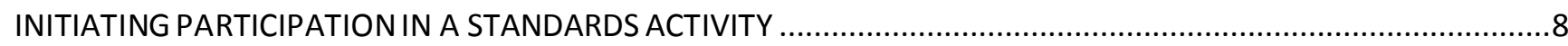

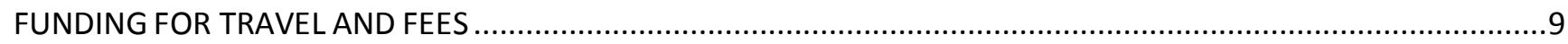

RESPONSIBILITIES OF NIST REPRESENTATIVESIN VOLUNTARY STANDARDS DEVELOPING ORGANIZATIONS'

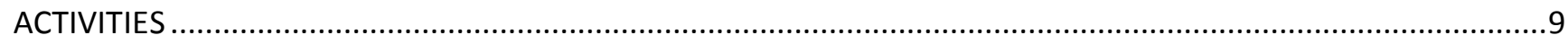

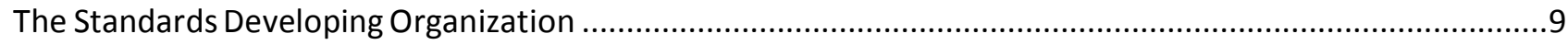

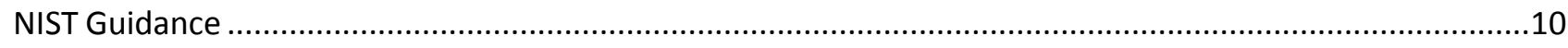

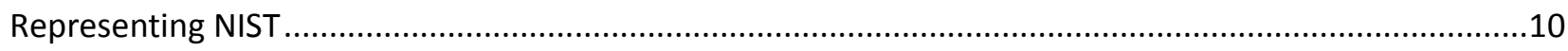

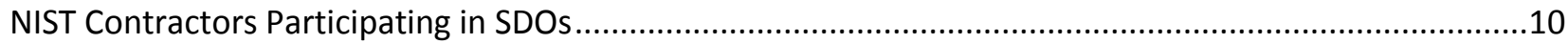

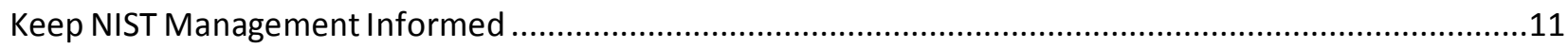

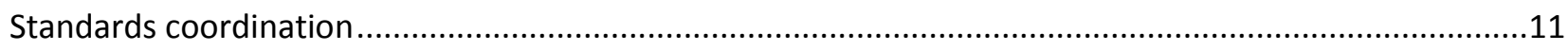

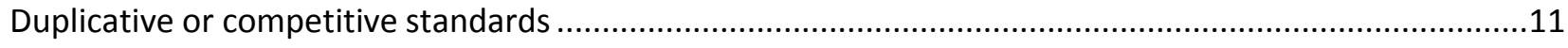

Update the Standards Committee Participation Database .......................................................................12

Ethical Obligations and Potential Antitrust Liability .............................................................................12

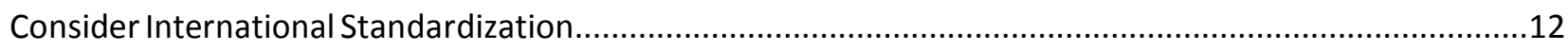

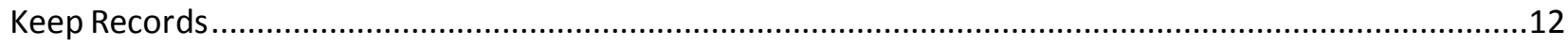

Promote the Metric System, Energy Efficiency, and Public Health and Safety .........................................12

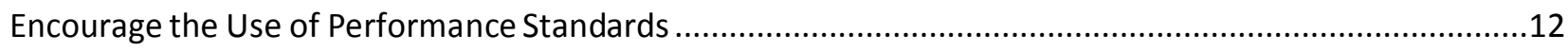

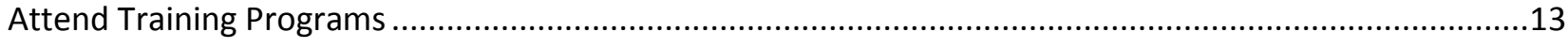

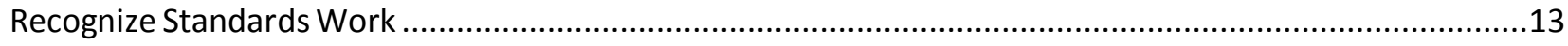

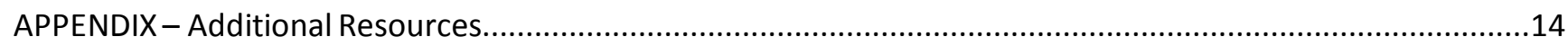




\section{INTRODUCTION}

\section{Background}

Standards have been an integral part of the mission ${ }^{1}$ of the National Institute of Standards and Technology (NIST) since its establishment (as the National Bureau of Standards) in the early 1900's. As part of its mission, NIST works with two types of standards, fundamental measurement standards, or physical standards, such as those for mass, length and time; and documentary standards that specify characteristics of products, processes and testing ${ }^{2}$. These Guidelines are relevant to documentary standards development. They provide a brief overview of the U.S. documentary standards process, followed by detailed guidance and resources available for NIST staff on their participation in the process.

\section{NIST's Role in Documentary Standards}

As the Nation's measurement laboratory, a primary focus of NIST has been the development of documentary standards for measurement and test methods. The main products of this focal area include standard test methods, standard test practices, and standard guides. In addition, members of NIST Operating Units (OU) participate in developing standards that are relevant to their areas of expertise. NIST staff have played a key role in developing standards for such areas as information technology, semiconductors, optical measurements, materials test methods and specifications, cyber-physical systems, sustainable and energyefficient manufacturing and construction and fire safety.

The Standards Coordination Office (SCO) works closely with the NIST laboratories to identify opportunities for NIST participation in standards-related activities, coordinate with the private sector and with other federal agencies on standards activities and programs, and monitor standards development and conformity assessment activities globally. In addition to training, SCO offers publications, policy analysis, and research. SCO provides access to standards documents and responds to standards related inquiries. Under the National Technology Transfer and Advancement Act (NTTAA), Public Law 104-113, SCO manages NIST's assigned responsibility to coordinate federal, state, and local technical standards and conformity assessment activities, with those in the private sector. The SCO manages the Commerce Standards Committee and coordinates the activities of the Interagency Committee on Standards Policy, which is chaired by the Director, SCO. This office also supports the NIST Director and Undersecretary for Standards and Technology's leadership of the National Science and Technology Council's Subcommittee on Standards.

\section{Process for Creating Documentary Standards}

NIST staff participate in the development of documentary standards in two primary ways: first, through the development of measurement science and research to support the standards; and second, in the development of the standards documents themselves, typically through a standards committee or working

\footnotetext{
${ }^{1}$ NIST's mission: "NIST promotes U.S. innovation and industrial competitiveness by advancing measurement science, standards, and technology in ways that enhance economic security and improve our quality of life."

${ }^{2}$ ISO/IEC Guide 2-2004, Standardization and related activities - General vocabulary, available in NIST's National Center for Standards \& Certification (NCSCl) reference collection (x4040 or StandardDocs@nist.gov).
} 
group. NIST does not usually develop voluntary consensus standards ${ }^{3}$, but participates actively in the development process and contributes significant technical expertise. In this respect, the U.S. system differs considerably from the government-driven standards systems in most other countries where national standards organizations are responsible for developing the standards used there. In fact, within the United States, there are hundreds of standards developing organizations (SDOs) that provide the infrastructure for the development of documentary standards. In the standards development process, government personnel participate in SDO activities along with representatives from industry, academia, and other organizations and consumers. It is important to emphasize that U.S. SDOs are private-sector organizations and that the federal government is simply one of many stakeholders and participants.

U.S. SDOs typically operate through a consensus process that is characterized by openness, transparency, balance, and due-process mechanisms for ensuring adherence to organizational procedures, including provision for appeals. SDOs usually form technical subgroups to develop their standards. SDO approval of such standards is based upon the consensus of the membership of the management level group designated by the SDO for final approval. Standards produced by these SDOs may be termed voluntary consensus standards, or voluntary standards. Compliance is voluntary except in cases where these standards are adopted as technical regulations or incorporated by reference into the Code of Federal Regulations or state or local laws and thus become mandatory.

\section{Standards Developing Organizations}

There are hundreds of standards developing organizations around the world, and the U.S. is home to an unusually large number of them due to its unique reliance on the private sector for developing standards. SDOs differ greatly in size, membership, number of standards produced, and scope of work. General categories include:

- $\quad$ Professional Societies

- Trade Associations

- Testing and certification organizations

- Industry Consortia

A list of SDOs can be found at several websites such as American National Standards Institute (ANSI) and the Society for Standards Professionals (SES). In the U.S., a majority of the standards are developed by a handful of SDOs.

Many U.S. domiciled SDOs develop standards which are used globally and are considered international standards. NIST staff are active in two major private-sector international standards organizations, namely the International Organization for Standardization (ISO) and the International Electrotechnical Commission (IEC) headquartered in Geneva, Switzerland. Membership in these organizations is based on national representation, and NIST staff participate as part of a U.S. delegation. Department of Commerce staff also participate in international treaty organizations such as the International Telecommunication Union (ITU).

\footnotetext{
${ }^{3}$ NIST develops one voluntary consensus standard - the ANSI/NIST-ITL 1-2011, NIST Special Publication 500-290 Data Format for the Interchange of Fingerprint, Facial \& Other Biometric Information.
} 


\section{Standards Coordination}

\section{Private Sector Coordination}

The American National Standards Institute (ANSI) is a private, non-profit organization (501(c)(3)) comprised of a federation of standards developers, government, industry, consumers, and other stakeholders. ANSI provides leadership and coordination for the U.S. standardization and conformity assessment activities and accredits standards developing organizations. ANSI does not itself develop American National Standards (ANSs); rather it facilitates development by providing procedures for establishing consensus among qualified groups. SDOs apply for and maintain accreditation through ANSI, and agree to follow the ANSI Essential Requirements: Due process requirements for American National Standards, which are a detailed set of requirements for SDO accreditation. ANSI-accredited standards development processes must achieve consensus, balance, transparency, due process and openness. More than 200 distinct entities are currently accredited under one of ANSI's three methods of accreditation (organization, committee or canvass). ANSIaccredited standards organizations develop standards addressing virtually every industry sector, enhancing the quality of life and improving the competitiveness of businesses operating in the global marketplace.

ANSI also provides leadership for the U.S. standards system in the international arena. ANSI is the U.S. Member Body to ISO, sponsors the U.S. National Committee for IEC and coordinates U.S. private sector standards development activities. In addition to the responsibilities set forth in the NTTAA, NIST and ANSI have signed a Memorandum of Understanding which recognizes NIST's and ANSI's roles in the national voluntary consensus standards system.

\section{Federal Coordination}

In 1996 Congress enacted the NTTAA), Public Law 104-113, which codified principles of the Office of Management and Budget (OMB) Circular A-119, Federal Participation in the Development and Use of Voluntary Consensus Standards and in Conformity Assessment Activities (1998). This legislation directs federal agencies to use voluntary standards whenever they are available and applicable in lieu of developing their own standards, thereby reducing the number of government unique standards for regulatory and procurement activities.

The legislation also asks agencies to promote participation by their staff in developing standards to ensure creation of standards that are usable by both federal agencies and the private sector.

The NTTAA directs NIST to coordinate the efforts of the agencies to meet the requirements set forth and report annually on federal use of standards. Further information on the NTTAA and OMB Circular can be obtained at www.standards.gov.

NIST supports the activities of the National Science and Technology Council's Subcommittee on Standards (SOS), a forum for senior officials of federal agencies to consider and address critical standards-related issues. The mission of the SOS is to: 
- $\quad$ engage government agencies on standards policy issues;

- $\quad$ articulate the U.S. model of a private sector led standards setting system with both public and private sector participation to domestic and international audiences; and

- $\quad$ increase awareness within the federal government of best practices in addressing standards policy issues.

In addition, NIST chairs and is the secretariat of the Interagency Committee on Standards Policy (ICSP) which provides advice and recommendations to the Secretary of Commerce and other Executive Branch agencies on matters related to standards policy. The ICSP, seeks to promote effective and consistent standards policies as well as foster cooperation between government, industry, and other private organizations involved in standards activities. In accordance with OMB Circular A-119, federal agencies are required to report annually on the number of voluntary consensus standards organizations in which they participated, as well as the number of their employees who participated. The Committee reports to the Secretary of the Department of Commerce (DOC) through the Director of NIST.

Finally, it should be noted that NIST staff are actively engaged in leadership and policy roles in numerous standards-related national, regional and international bodies including the American National Standards Institute (ANSI), the Pacific Area Standards Congress (PASC), and the Pan American Standards Commission (COPANT). NIST also engages in conformity assessment related activities ${ }^{4}$, defined by ISO/IEC $17000^{5}$ as the "demonstration that specified requirements relating to a product, process, system, person or body are fulfilled. SSG actively monitors and participates in standards development and conformity assessment activities, consults with other federal agencies on standards policy issues, offers workshops and educational seminars for domestic and international audiences, and provides standards-related research and information services.

\section{INITIATING PARTICIPATION IN A STANDARDS ACTIVITY}

Up to this point, we have presented the "big" picture of standards activities by identifying some of the key players, important procedures, and coordination activities. We now turn to procedures for you, the NIST employee, as you participate in the development of standards.

There are many ways to participate in documentary standards development activities. You may choose to be a member of a committee, a subcommittee or a working group; you may also choose to serve in a leadership role such as the secretary or chair of a standards committee. The SDOs with which you choose to become involved and the roles you serve should be driven by the mission of your OU as well as by NIST's overall mission. The activity should allow you to incorporate NIST research and technical expertise into a standard that is needed by industry, government and other sectors of the U.S. and/or international community. Additionally, the SDO with which you participate must also be listed on NIST's List of Approved Standards

\footnotetext{
${ }^{4}$ As its name states, this important activity deals with the various mechanisms for ensuring that a product does, in fact, meet a specified standard. The U.S. conformity assessment system is outlined in NISTIR 6014, The ABC's of the U.S. Conformity Assessment System, April 1997.

${ }^{5}$ ISO IEC 17000 - Conformity assessment - Vocabulary and general principles
} 
Bodies. If the SDO is not listed, you may submit a request for approval by following the process described in NIST's Policy and Order Participation in Documentary Standards Activities.

The decision to participate in standards developing organization activities is made by you in conjunction with your management based on your unit's mission and goals, resource commitments, and the technical competence required. Once the decision is made, you and your manager should then add an appropriate element to your Performance Plan. This should include a clear statement of your time and resource commitment to the activity, as well as a set of goals and milestones. Your accomplishments should be reviewed according to your laboratory's normal practice concerning standards-related activities.

Standards Services maintains the Standards Committee Participation Database (SCPD) which contains information ${ }^{6}$ on NIST staff involvement in the standards developing activities of various organizations. NIST staff are required to report this information in order to keep the database current and accurate. This information is used by NIST to report to the Office of Management and Budget as required under the NTTAA and as part of NIST's overall performance metrics in documentary standards activities. NIST tracks the number of DOC staff participating in standards activities, a list of the SDOs with which they participate.

\section{FUNDING FOR TRAVEL AND FEES}

NIST maintains a list of standards bodies approved by its Director for institutional (NIST) membership. OUs are permitted to pay for memberships to organizations on this list of approved standards bodies. NIST OUs support staff travel to standards committee meetings in the same way that they support other official travel. Individual membership fees are not required when staff represent NIST at ANSI or certain other standards bodies to which NIST pays institutional membership fees.

In addition, NIST OUs pay administrative service fees to ANSI when NIST staff become secretariats of committees of international organizations such as ISO and IEC, of which ANSI is the recognized U.S. member body. The funds are provided by the appropriate OUs, and SCO coordinates the payment of secretariat fees with both the OUs and ANSI.

\section{RESPONSIBILITIES OF NIST REPRESENTATIVES IN VOLUNTARY STANDARDS DEVELOPING ORGANIZATIONS' ACTIVITIES}

\section{The Standards Developing Organization}

You should become familiar with the purpose, organization, structure and operating procedures of the SDO you have selected. Participants in standards committees should review the purpose and scope of each particular activity, and should seek clarification of any ambiguities. Participants should also be aware that the use or abuse of standards procedures by participants in standards developing activities in order to restrict competition is improper and violates various federal and state antitrust statutes; such violations are subject to civil and criminal prosecution.

\footnotetext{
${ }^{6}$ Information collected includes the SDO, committee name and number (if applicable), and position on the committee.
} 
Many domestic SDOs use Robert's Rules of Order to conduct meetings. Note that international SDOs may not follow these rules. You should become familiar with these common practices in order to be effective.

Standards Services offers training at NIST on the fundamentals of standards, how to effectively participate in standards development activities, conformity assessment and more. ANSI and SDOs also periodically offer training courses on effective participation as well as specific operating procedures. More details on training are contained in the NIST Policy below.

\section{NIST Guidance}

\section{Representing NIST}

NIST Directives 805 establish policies and procedures for the acceptance and maintenance of memberships on government and non-government standards and professional committees working in areas related to NIST activities. As noted there, "...staff members are encouraged to participate in domestic and international standards activities, whenever such participation is in the public interest and is compatible with NIST priorities and available resources. Those who participate in activities related to the professional basis of their employment carry an inseparable identification with NIST. Consequently, they have a fundamental obligation to know and act in conformity with established policies and program objectives of NIST, DOC, and the Administration."

You should be familiar with NIST's positions on major policy issues and, if necessary, be prepared to articulate official positions. In most instances, NIST staff participate in aspects of standards development that are closely related to their technical expertise. Nevertheless, issues related to general governmental policy or sensitive issues may arise. NIST participants should never express personal opinions on significant policy issues since they might be construed to be official NIST policy. Seek the help and advice of your OU management as well as SCO staff on policy and procedural matters. Try, when possible, to coordinate your position with other NIST, Department of Commerce or federal agency representatives on your committee.

\section{NIST Contractors Participating in SDOs}

When NIST uses contractors to support its participation in an SDO, the following guidance should be followed when drafting the Statement of Work (SOW):

1. NIST personnel should serve as the NIST principal representatives to an SDO.

2. NIST contractors may attend SDO meetings with or without the NIST principal representative, may participate in SDO discussions, may perform technical work related to standards setting, but may not represent NIST to an SDO.

3. NIST contractors may never express personal opinions on significant policy issues since they might be construed to be official NIST policy, nor may they express opinions on behalf of NIST.

4. NIST contractors should be cognizant of all relevant NIST technical contributions and positions, but may not express such positions on behalf of NIST.

5. NIST contractors do not have the authority to decide on the NIST technical contributions or positions, but may be tasked to develop inputs for NIST, with NIST oversight.

6. NIST contractors that are appointed to SDO officer positions (e.g., project editor, convener, chairperson) may only do so in their private capacity, not as a representative of NIST.

7. NIST contractors attending SDO meetings should identify themselves as such to avoid creating an 
impression in the minds of the other participants that they are Government officials.

8. NIST personnel and management should provide appropriate oversight of contractor performance by requiring timely and periodic reports and meetings with NIST contractors.

9. NIST personnel and management should ensure that contractors are cognizant of the after award requirements of the organizational conflict of interest contract clause. ${ }^{4}$

\section{Keep NIST Management Informed}

You should keep your supervisor informed of significant developments, both technical and policy, that occur at committee meetings. In addition, certain "high-impact" issues should be brought to the attention of your OU management and Standards Services. An issue can be considered to have high impact if it meets any of the following criteria:

1. It may be brought to the attention of the NIST Director or the Secretary of Commerce by one or more outside groups, such as Congress, another federal agency, a trade organization or standards developer, a firm or an influential individual.

2. It requires broad coordination across NIST.

3. It could entail anti-trust violations or even the concern of potential anti-trust violations.

4. It involves intellectual property issues such as patent claims and licensing fees.

5. It generates a need for policy guidance regarding appropriate limits of NIST responsibility, whether technical or financial.

6. It may result in outside criticism of NIST by reputable persons or organizations.

7. It would have significant impact on U.S. international trade or on the health, safety, or environmental conditions of U.S. citizens.

\section{Standards coordination}

NIST is required by U.S. Government policy to coordinate its position with other federal agencies who are participating on the same standard prior to voting. This is required by the Office of Management and Budget (OMB) Circular A-119 Revised (February 10, 1998): Federal Participation in the Development and Use of Voluntary Consensus Standards and in Conformity Assessment Activities, 15. b. (3). An excerpt from the OMB Circular states: "Ensuring, when two or more agencies participate in a given voluntary consensus standards activity, that they coordinate their views on matters of paramount importance so as to present, whenever feasible, a single, unified position and, where not feasible, a mutual recognition of differences."

However NIST and other agencies are not obligated to vote for the same position on a ballot. Their different missions may require them to take different positions upon occasion.

\section{Duplicative or competitive standards}

In the absence of any non-resolvable substantive technical issue, NIST believes that the U.S. Government should remain neutral with respect to technology and standards choices. The availability of a wide array of technologies and standards allows the U.S. Government to best meet its information technology needs, while

\footnotetext{
${ }^{4}$ 1352.209-71 ORGANIZATIONAL CONFLICT OF INTEREST (MAR 2000)

(b) The Contractor agrees that if an actual or potential organizational conflict of interest is discovered after award, the Contractor will make a full disclosure in writing to the Contracting Officer. This disclosure shall include a description of actions which the Contractor has taken or proposes to take, after consultation with the Contracting Officer, to avoid, mitigate, or neutralize the actual or potential conflict. 
retaining the ability to exchange data.

\section{Update the Standards Committee Participation Database}

NIST staff participating in standards developing activities should make sure they and their committee memberships are included in the Standards Committee Participation Database. The database can be accessed at Standards Services intranet site. Further information concerning the database, or related issues, can be obtained by contacting: Standards Services, x2490; e- mail: scpd@nist.gov.

\section{Ethical Obligations and Potential Antitrust Liability}

When you participate in standards-developing activities, you will almost certainly be involved with representatives of the private sector, imposing numerous responsibilities, ethical obligations, and possible antitrust considerations. Federal employees are subject to constraints on conduct that may not apply to your private-sector counterparts. These include limitations and restrictions on acceptance of gifts, meals, travel expenses, and the like. If you have any questions, or if you are concerned about ethics issues, call the Ethics Division of the DoC Office of General Counsel at 202-482-5384 for a full explanation of all ethical rules pertaining to working with the private sector on standards activities. Additional information on these obligations is available on the Standards Services intranet website. You should be aware that federal agencies and employees have some protection against antitrust liability with respect to standards activities consistent with their agency mandates, and should not be deterred from participating in standards work for fear of such liability.

\section{Consider International Standardization}

The United States has obligations specified under the Trade Agreements Act of 1979 (1995 revision) and the World Trade Organization Agreement on Technical Barriers to Trade. Therefore, you should be aware of international standards and standardization activities related to your standards committee work. You should also be mindful, per NIST policy, to promote the inclusion of U.S. technology, both existing and emerging, in national and international standards.

\section{Keep Records}

All participants should maintain a file of committee-related information, including the committee's by-laws, membership lists, notes of meetings, final ballots, and relevant correspondence. You or your unit should retain this file for at least five years after the conclusion of the standards activity, and follow NIST procedures for records retention.

\section{Promote the Metric System, Energy Efficiency, and Public Health and Safety}

Whenever appropriate, you should encourage use of the metric system, environmentally sound and energy efficient materials, products, systems, services, or practices and consider issues related to public health, safety, and protection of the environment.

\section{Encourage the Use of Performance Standards}

Whenever appropriate, you should encourage the development and use of performance standards.

Performance based standards generally are less likely to impede innovation than design standards. However, design standards may sometimes be more appropriate, particularly for describing test methods or procedures. Keep in mind that design standards or references to patented devices, materials or processes 
may deter technical progress and may be prohibited by some SDOs.

\section{Attend Training Programs}

Standards Services offers NIST-wide training on the fundamentals of documentary standards and conformity assessment. Smaller workshops can also be tailored to meet the specific needs of a requesting OU, division or group. Presentations and discussions may include topics such as the U.S. standards system and key players in the standards development community; how standards are developed; the U.S. government and NIST's roles and responsibilities under the NTTAA; how to be an effective participant and leader in the development of consensus standards; conformity assessment and why standards and the assessment of conformity to standards are important; how standards affect global trade and trade agreements; NIST resources available for assistance; and more. For more information visit the Standards Services intranet site or send a message to standardstraining@nist.gov.

A number of helpful training programs are also provided by ANSI and many SDOs with topics ranging from general standardization subjects to specific training for committee members. For a list of some of these courses, go to www.standards.gov or to a specific SDO's website.

\section{Recognize Standards Work}

NIST annually presents the Edward Bennett Rosa Award to recognize outstanding achievement in or contributions to the development of meaningful and significant engineering, scientific, or documentary standards either within NIST or in cooperation with other government agencies or private groups. The award consists of an engraved plaque and a $\$ 5,000$ honorarium. If you are aware of a NIST participant who meets the announced criteria, consider recommending him/her to your supervisor for nomination. Additional information on this award can be found at the NIST intranet site or by contacting NIST's Human Resources Management Division. 


\section{APPENDIX - Additional Resources}

Below are additional resources that provide greater detail on specific areas of interest regarding documentary standards. These and more may be found in the Publications section of the Global Standards Information site: http://gsi.nist.gov/global/index.cfm/L1-5/L2-44/A-327

- ABC's of Standards Activities

- ABC's of the U.S. Conformity Assessment System

- A Review of U.S. Participation in the ISO and the IEC

- Measuring Benefits from the National Technology Transfer and Advancement Act

- Report on the Use of Voluntary Standards in Regulation in the United States

- Selected Impacts of Documentary Standards Supported by NIST 